\title{
Movement-Versus Sporting-Based Physical Education in Elementary Schools: Does Either Ensure Quality?
}

\author{
Joseph John Scott \\ Health and Physical Education, School of Education, Edith Cowan University, Australia \\ $\triangle$ joseph.scott@ecu.edu.au
}

\begin{abstract}
Within the physical education literature, there remains to be contentions between the effectiveness of sporting- and movement-based approaches. Whilst both have noted strengths and weaknesses, there is little research into whether either is leading to quality physical education in Australian elementary schools. This paper therefore examines two of the common models based approaches to teaching physical education in elementary schools against the five interrelated propositions of the Australian Curriculum to determine if either pedagogical approach is leading to quality physical education. This paper draws on current literature, curriculum frameworks and pedagogical recommendations to determine the value of a models based approaches to physical education in relation to quality. Examinations indicate that both the sports and movement based approaches can address the five key propositions that underpin the Australian Curriculum, however quality is dependent on appropriate implementation by qualified and skilled teachers. Teacher education and pedagogical knowledge is paramount for the implementation of quality physical education. Further investigation and exploratory research is required to determine if the model based approaches are being effectively being introduced by both generalist and specialist health and physical education teachers in elementary school settings.
\end{abstract}

Keywords: curriculum, elementary, movement, physical education, sport.

How to Cite: Scott, J. J. (2019). Movement-Versus Sporting-Based Physical Education in Elementary Schools: Does Either Ensure Quality? Mimbar Sekolah Dasar, 6(2), 267-276. doi:10.17509/mimbar-sd.v6i2.17432.

INTRODUCTION While PE has had a contentious history, it has been integrated into school curriculum globally for over a century (Puhse \& Gerber, 2005). In 1978, the United Nations Educational, Scientific and Cultural Organisation (UNESCO) developed the Charter of Physical Education and Sport which outlined that physical education (PE) is a fundamental right for all, and is an essential element of lifelong education. UNESCO also recognised the important role of $P E$ in reducing the significant health burden related to lifestyle diseases (United Nations Educational Scientific and Cultural Organisation, 2015). In the digital age, the advancement of handheld technology, televisions, computers, video games has contributed to a significant increase of physical inactivity, sedentary behaviour and lifestyle related disease in young people (Okely A. D. et al., 2012).

While traditional approaches in health and PE have predominantly focused on the development of pre-requisite skills for common sports, recreational activities and physical fitness (Brooker \& Clennett, 2006), the rise in non-communicable lifestyle and diet related diseases during the 1980's to early 2000's led to a greater emphasis on worldwide health promotion and 
Joseph John Scott, Movement-Versus Sporting-Based Physical Education...

education. As such, the governed curriculum and learning area of PE has changed from focusing primarily on 'sport and fitness' to explicitly linking PE pedagogical practice to curriculum learning outcomes, with the overarching aims being the development of student's skills, psychomotor competencies, values and holistic understandings of health and well-being (Australian Curriculum, 2012). In the literature, this has commonly been termed as 'quality' HPE (McLennan \& Thompson, 2015).

The definitions of quality PE within the literature are diverse and implementation of quality curriculum based on policy has remained problematic globally (United Nations Educational Scientific and Cultural Organisation, 2015). UNESCO defines "quality physical education" as planned, progressive and inclusive learning experiences that are developmentally age appropriate, and which encourage students to acquire psychomotor, social and emotions skills while developing cognitive understandings (United Nations Educational Scientific and Cultural Organisation, 2015). This is detailed and specific definition, however unfortunately UNESCO does not provide guidelines on pedagogical practice, nor does it tell teachers how to implement quality HPE into their lessons and meet mandated curriculum. The Australian Curriculum: health and physical education (ACHPE) learning area is aligned to UNESCO's definitions of quality physical education.
When creating the ACHPE, five interrelated propositions were developed to guide pedagogical action and ensure evidencebased quality (Australian Curriculum Studies Association, 2018). There is however, limited research investigating the relationship of the interrelated propositions and common pedagogical approaches to teaching PE. More recently, has been a shift in pedagogical approach and the notion of movement based practice has emerged as the preferred way to teach PE in elementary schools and connect with mandated ACHPE (Kirk, 2013). However, there remains to be inconsistencies in the utilisation and implementation of sportteaching and movement based approaches in Australian elementary schools.

\section{SPORT-BASED AND MOVEMENT-BASED APPROACHES}

Sporting-based approach (SBA): This has also been referred to as "sport-teaching approach". The SBA attempts to educate the students to become 'sports literate' which has also been termed the teaching of 'sports literacy' (Drummond \& Pill, 2011). The term 'sport' refers to a variety of physical activity movements distinguished by accepted codifications of rules to enable participants to distinguish specific types of sporting activities. The term 'sports literacy' refers to the functional use of sport knowledge for active and engaged citizenship (Pill, Penney D., \& Swabey K., 2012). In 2010, Pill provided four distinct areas for knowledge and understanding of 
sport. These are: i) Sport is an applied, practised and situated set of skills; ii) Sport creates embodied meaning, and meaning that can be communicated, interpreted, understood, imaged and used creatively; iii) Sport creates a 'text', which can be read for understanding; and iv) understanding sport requires a learning process (Pill, 2010). Sport literacy approaches aim to provide students with a meaningful and authentic sporting experiences and focus on building sport specific skills so that they can become competent and enthusiastic sportspersons and enjoy being physically active (Siedentop, Hatsie, \& Mars, 2011).

Movement-based approach (MBA): The MBA aims to make students physical literate and proficient in movement, rather than learn a situated specific set of skills for sports. This approach focuses on building and refining body positioning and movement skills for physical proficiency for a broad range of applications including, but not limited to sport (e.g. active play, minor games, recreational activities, dance, gymnastics) (Whitehead, 2013a). It has a dominant focus on the development and application of a range of body fundamental movement skills (FMS), such as, body management, locomotor and object manipulation. The FMS skills have been reported as the precursor patterns for more specialised and complex movements and have been identified as important for children's, physical, cognitive and social development (Lubans, Morgan, Cliff, Barnett, \& Okely, 2010). The aim of this approach is to build students competence and confident when engaging in all types of movement so they enjoy being physically active. This has led to the emergence of the term 'physical literacy'. The concept of being physical literate is the possessing the motivation, confidence, competence, knowledge and understanding to maintain a physically active life (Lundvall, 2015).

Whilst both SBA and MBA have noted strengths and limitations when taught in isolation, there is little research into whether either of these models are leading to quality physical education in Australian elementary schools. This paper will draw on current literature, curriculum frameworks and pedagogical recommendations to investigate the SBA and MBA address the five interrelated propositions of the ACHPE to determine if either pedagogical approach is ensuring quality. This paper attempts to address the following research questions:

1. How does the SBA align to the five interrelated propositions of the ACHPE?

2. How does the MBA align to the five interrelated propositions of the ACHPE?

3. Would a blended dichotomous approach be more appropriate to ensure quality PE?

\section{THE STRUCTURE OF tHE AUSTRALIAN CURRICULUM: HEALTH AND PHYSICAL EDUCATION}

The ACHPE is organised into two content strands: Personal, social and community 
health and movement and physical activity. Each strand contains content descriptions which are organised under three sub-strands: i) being healthy, safe and active; ii) communicating and interacting for health and wellbeing; iii) contributing to healthy and active communities; iv) moving our body; v) understanding movement; vi) Learning through movement (Australian Curriculum, 2017).

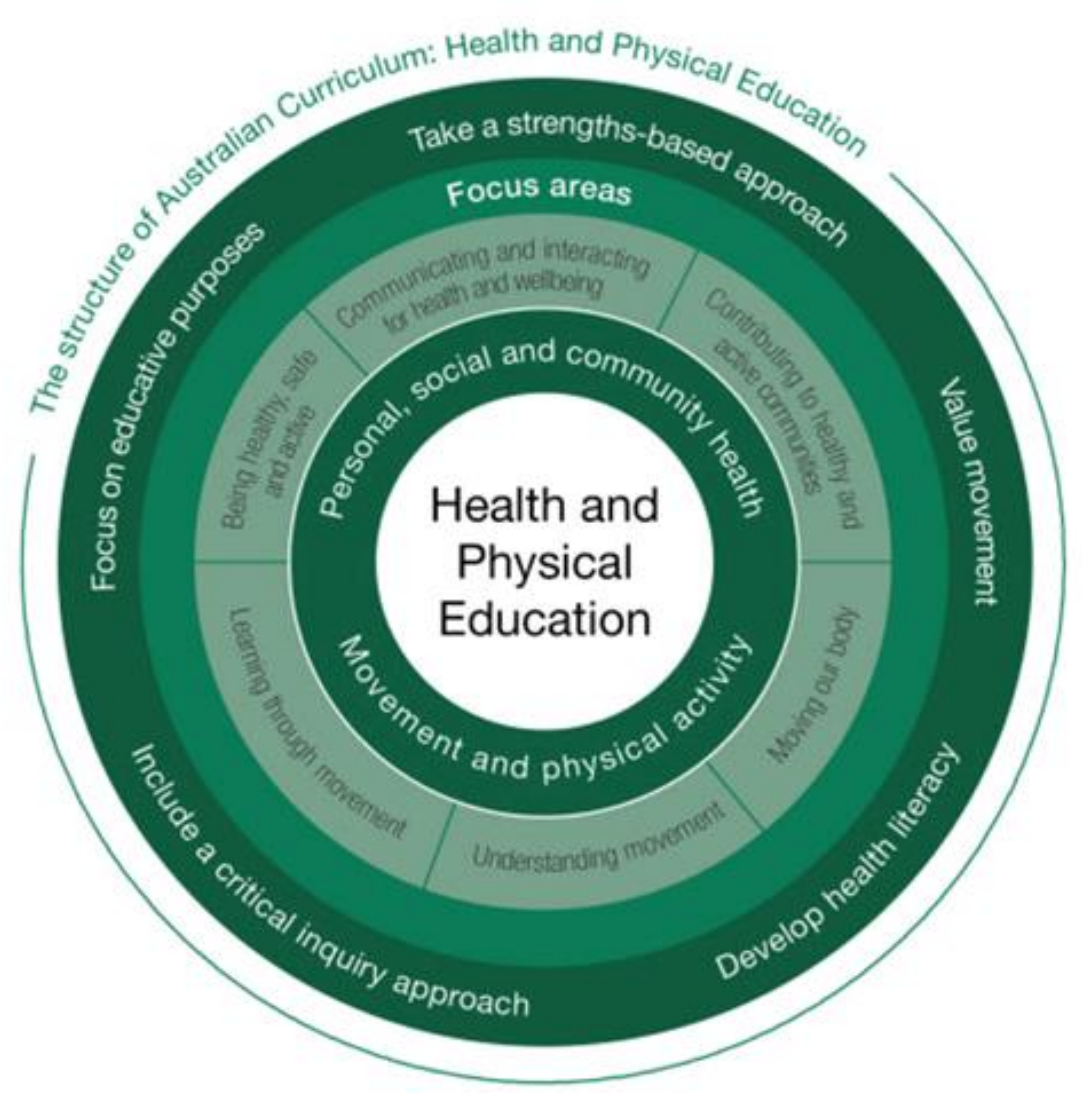

Figure 1. The structure of the Australian Curriculum: Health and Physical Education (Australian Curriculum, 2017).

\section{THE AUSTRALIAN CURRICULUM HEALTH AND PHYSICAL EDUCATION: FIVE INTERRELATED PROPOSITIONS}

The ACHPE has been shaped by five interrelated propositions. The following discussion examines both SBA and MBA in relation to each of the five propositions in the curriculum framework. The five propositions are:

1. Focus on the educative purpose

2. Take a strengths based approach

3. Value movement
4. Develop 'health literacy' skills

5. Include a critical inquiry based approach

\section{Focus on the Educative Purpose}

This key proposition reinforces that all physical education lessons should have an educative purpose. It highlights that all learning experiences should be developmentally appropriate and provide students with an opportunity to create, synthesise, apply and evaluate knowledge 
whilst building physical skills (Australian Curriculum Assessment and Reporting Authority, 2018). The ACHPE curriculum is underpinned by the principals of many fields including physiology, nutrition, biomechanics and psychology (Australian Curriculum, 2012). Previous research focusing on elementary curriculum and pedagogy have often marginalised PE from the other learning areas and referred to it as non-purposeful, non-academic or non-cognitive education (Alexander \& Luckman, 2001). PE curricula has been criticised with some researchers reporting that the learning has been limited to fundamental movements, motor and sport performance skills (Lumpkin, 2005). It has been reported that one reason that elementary PE has frequently concentrated on developing technical expertise in sport is the PE teachers' narrow interpretation of the curriculum and focus of teaching (Brooker \& Clennett, 2006).

Due to the progressive and needs based evolution of the PE curriculum, there remains a prominence of embedded sport. Whilst it has been reported that sport in PE can enhance students access to practices that enable them to make positive contributions to society, skilled teachers with an expertise in interpreting the ACHPE are required to ensure that pedagogical approaches to PE are implemented correctly to promote application, evaluation and synthesis of knowledge. Novel pedagogical approaches such as MBA's, attempt to increase physical literacy for application across a range of areas and advocate for the delivery of current content in the PE field which is socially constructed and hence relevant. The MBA provides settings where students can explore their learning, experience their body during physical activity and solve problems by interacting with others and the environment (Whitehead, 2013b). Although SBA and MBA's are fundamentally different, both approaches provide educationally rich environments where the students engage in explorative learning through movement to build physical competencies.

\section{Take a Strengths Based Approach}

This key proposition focuses on supporting students to develop their strengths and be an advocate for their own health. Rather than focusing on potential risks for health, the ACHPE has a larger focus on providing knowledge, understandings and skills so that students have the ability to make sound choices and decisions about their own health. This key idea affirms that students and communities have particular strengths that can be utilised to enhance their well-being, movement competence and level of participation in physical activity (Australian Curriculum Assessment and Reporting Authority, 2018). The SBA teaches sports literacy with the overarching goal for students to creatively use this knowledge to become active sport engaged citizens. Research suggests that application of holistic understandings of sport will have a positive impact on physical, social and emotional health (Pill et 
Joseph John Scott, Movement-Versus Sporting-Based Physical Education...

al., 2012). In addition, team memberships and student centred learning with an SBA promotes personal and social development as well as cooperation, student leadership, trust and problem solving skills (Wallhead \& O'Sullivan, 2005).

The MBA focuses on creating environments where students can practise skills through high active modified and minor games. Students are required to collaboratively work together to explore their learning, apply strategies and tactics to achieve identified outcomes in game environments (Casey \& MacPhail, 2018). Whilst the SBA has many positives, it has been criticised as potentially not serving the interests of many students, especially those elementary students who have lower skill levels (Araújo, Mesquita, \& Hastie, 2014). Consequently, contemporary PE approaches (such as, the $M B A$, aim to create inclusive student centred learning experiences through modifiable environments to suit the needs of the students and aim to support existing strengths. If implemented properly, both MBA and STA provide opportunities where students are required to reflect on their learning, and hence, build students' knowledge and understandings of their own health so that they are able to make informed, timely and healthy decisions.

\section{Value Movement}

This key proposition reinforces that all learning experiences should provide a variety of opportunities for students to enhance movement competence and confidence. The pedagogy should explicitly focus on refinement of developmentally appropriate movements and aim to enhance a range of personal and social skills (Australian Curriculum, 2012). PE learning experiences should promote the appreciation of movement as a valuable tool for lifelong health (Australian Curriculum Assessment and Reporting Authority, 2018). Both the SBA and MBA share an overarching goal of enhancing students' knowledge and understandings of physical activity and the potential positive impact it can have on physical, social and emotional health. As the MBA has a more dominant focus movement proficiently in a range of learning environments that align to the ACHPE curriculum focus areas (for example: active play and minor games, challenge and adventure activities, rhythmic and expressive activities and FMS), it is, consequently, a superior approach to SBA when addressing this proposition (Australian Curriculum, 2012).

\section{Develop 'Health Literacy' Skills}

Health literacy is defined as an individual's ability to gain access to, understand, and utilise health knowledge and services so that they are able to maintain good health and well-being. To develop health literacy students need to be provided with a range of opportunities to access, analyse, critique health information and services (Australian Curriculum Assessment and Reporting Authority, 2018). As both the SBA and MBA are approaches to teaching PE rather than health specifically, the dominant focus is on 
physical literacy rather than health literacy skills; hence are both limited in addressing this proposition area. However, as stated above, regardless of the approach taken, all PE learning experiences should be educative, enhance the development of health knowledge and understanding and promote critical an higher order thinking (Dudley D., Telford, Peralta, Stonehouse C., \& Winslade., 2018). To properly address this proposition, health literacy outcomes and assessment should be embedded into all PE programs.

\section{Include a Critical Inquiry Based Approach}

This key idea aims to engage students in critical inquiry by creating learning experiences that involve deeply analysing and evaluating social, environment and contextual factors that influence health and movement behaviours. Students should be provided with opportunities to research, analyse, apply and appraise health and movement knowledge (Australian Curriculum Assessment and Reporting Authority, 2018). As suggested by Pill (2010), for students to properly understand the multifaceted nature of sport, students are not only required to practise situated set of skills, but also to be able to create embodied meaning of sport that can be interpreted, understood, evaluated and creatively applied (Pill, 2010). Therefore the SBA approach has the ability to provide educationally rich, contextualised opportunities for students to analyse health and movement knowledge and be involved in critical inquiry. Similarly, the MBA focuses on building a holistic view of movement and health. Students can use their knowledge and understanding of physical activity and movement to question social, cultural and political factors that influence health and wellbeing. By including critical enquiry, both the SBA and MBA's can challenge students to problem solve, analyse and evaluate the complex sociocultural issues that affect health and physical activity participation, hence make informed decisions about their own health.

\section{RECOMMENDATIONS}

\section{Hybridisation of Approaches}

Both SBA's and MBA's have noted strengths and weaknesses when aligning to the five propositions of the ACHPE. One solution to addressing the weaknesses of implementing isolated approaches is the hybridisation (Casey \& MacPhail, 2018). A recent systematic review of 20 pedagogical models for teaching PE in years 1- 12 found that there are advantages to teaching hybridised models over isolated approaches as there is the ability to address a multiple learning outcomes and domains of the curriculum. However, the review identified that for a hybridised approach to be successful there were three key features were identified: i) teacher commitment, pedagogical content knowledge, teacher experience and education (González-Víllora, Evangelio, Sierra-Díaz, \& Fernández-Río, 2018). The introduction of models based approaches (such as STA or MBA), into the 
Joseph John Scott, Movement-Versus Sporting-Based Physical Education...

school PE program is complex and preliminary research has suggested that a large proportion of elementary teachers are not confident or competent enough to implement models based PE /Casey \& MacPhail, 2018; Morgan \& Bourke, 2008). Further research in this area is warranted to investigate the implementation of models based practice.

\section{Skilled Teachers with Deep Pedagogical and Content Knowledge}

Based on the definition from UNESCO, the quality of the learning experience is hinged on the education and skill level on the teacher (United Nations Educational Scientific and Cultural Organisation, 2015). UNESCO highlights that teachers that possess deep pedagogical content knowledge and the ability to provide valuable and meaningful learning experiences will ensure their students build skills, knowledge and the self-efficacy to lead healthy and active lifestyles (Dudley D. et al., 2018). This confirms the previous decades of research from the International Council of Sport Science and Physical Education (ICSSPE) which have recognised the importance of teacher education and resources to effectively improve the quality of PE worldwide (International Council of Sport Science and Physical Education, 1999; United Nations Educational Scientific and Cultural Organisation, 2015). Consequently, regardless of whether an approach is dominantly focusing on sport literacy or movement proficiency; if taught in isolation or hybridised; it will not ensure quality unless is implemented by a skilled well qualified teacher with the proper resources. In addition to skilled teachers with specific content knowledge, a curriculum that is underpinned by a quality education framework is also needed.

\section{Tailoring Approach to Needs of the Students}

A blended dichotomous model may better address the five interrelation propositions of the ACHPE than an approach used in isolation, but as teacher education/experience, pedagogical and content knowledge remains varied internationally, there continues to be no recommended generalisable approach to teaching PE. It is therefore reasonable to identify the interests and needs of the elementary students, school and community and tailor a multidimensional approach to teaching sport literacy and movement proficiency. This will ensure that the pedagogical approach is appropriate and developmentally suited to the students' needs and skill level. Younger elementary students will require approaches that provide a large amount of skill practice time to build movement proficiency and FMS skills, such as the MBA. Whereas, upper elementary students may be more suited to approaches that provide opportunities for ongoing skill development, skill refinement and application of skills in a range of environments, such as the SBA. This, in conjunction with a qualified and skilled teacher that has access to the required resources should ensure that a quality PE program which promotes holistic 
understandings and knowledge of the importance of physical activity and health is delivered.

\section{CONCLUSION}

The five interrelated propositions of the ACHPE promote the use of diverse learning experiences to build a holistic understanding of health and movement behaviours. Although both SBA and MBA have noted strengths and weakness, a dichotomous model that encompasses the strengths of both sporting and movement based approaches (and potentially strengths of other existing models based approaches), could potentially better address the five propositions of the ACHPE. Further research in this area is warranted to determine the quality of PE provided through a dichotomous or hybridised approaches. Prior to selecting an approach to teaching PE, teachers need to identify the needs and skill level competency of their students to ensure content is developmentally appropriate. Based on literature and curriculum framework, quality of PE will be guided by approach and implementation. Although we have seen a recent reform in $\mathrm{PE}$ curriculum across Australia, the quality of PE appears to be dependent on teacher education, expertise, pedagogical and content knowledge. Further investigation and exploratory research is required to determine if the sporting and movement based approaches are being effectively being introduced elementary teachers in Australian schools.

\section{REFERENCES}

Alexander, K., \& Luckman, J. (2001). Australian Teachers\&iacute; Perceptions and Uses of the Sport Education Curriculum Model. European Physical Education Review, $7(3)$ 243-267. doi:10.1177/1356336X010073002

Araújo, R., Mesquita, I., \& Hastie, P. A. (2014). Review of the Status of Learning in Research on Sport Education: Future Research and Practice. Journal of Sports Science \& Medicine, 13(4), 846858.

Australian Curriculum, A. a. R. A. (2012). The shape of the Australian Curriculum: Health and Physical Education. Retrieved from http://docs.acara.edu.au/resources/S hape of the Australian_Curriculum_H ealth_and_Physical_Education.pdf

Australian Curriculum, A. a. R. A. (2017). The health and physical education structure. Retrieved from https://www.australiancurriculum.edu. au/f-10-curriculum/health-andphysical-education/structure/

Australian Curriculum Assessment and Reporting Authority. (2018). Key ideas: health and physical education propositions. Retrieved from https://www.australiancurriculum.edu. au/f-10-curriculum/health-andphysical-education/key-ideas/

Australian Curriculum Studies Association. (2018). Chapter 9 Health and physical education: transformative potential, propositions and pragmatics. In The Australian Curriculum: promises, problems and possibilities. Canberra, Australia: ACSA.

Brooker, R., \& Clennett, A. (2006). Teaching physical education in contemporary Australian school education: Rethinking teachers curriculum and pedagogical work. Australian Association for Research in Education, AARE Conference publication.

Casey, A., \& MacPhail, A. (2018). Adopting a models-based approach to teaching physical education. Physical Education and Sport Pedagogy, 23(3), 294-310. doi:10.1080/17408989.2018.1429588

Drummond, M., \& Pill, S. (2011). The role of physical education in promoting sport 
participation in school and beyond. Sydney, NSW: In S. Georgakis \& K. Russell (Eds.) Sydney University Press.

Dudley D., Telford, A., Peralta, L., Stonehouse C., \& Winslade. (2018). Teaching quality health and physical education. South Melbourne, VIC: Cengage Learning Australia.

González-Víllora, S., Evangelio, C., SierraDíaz, J., \& Fernández-Río, J. (2018). Hybridizing pedagogical models:A systematic review. European Physical Education Review. Retrieved from http://journals.sagepub.com/doi/abs/ 10.1177/1356336X18797363 doi:10.1177/1356336x18797363

International Council of Sport Science and Physical Education. (1999). The Berlin agenda for action for government ministers. Retrieved from http://www.icsspe.org/content/worldsummit-physical-education

Kirk, D. (2013). Educational Value and Models-Based Practice in Physical Education. Educational Philosophy and Theory, 45(9), 973-986. doi:10.1080/00131857.2013.785352

Lubans, D. R., Morgan, P. J., Cliff, D. P., Barnett, L. M., \& Okely, A. D. (2010). Fundamental Movement Skills in Children and Adolescents. Sports Medicine, 40(12), 1019-1035. doi:10.2165/11536850-000000000-00000

Lumpkin, A. (2005). Introduction to physical education, exercise science, and sport studies. New York, NY: McGraw Hill.

Lundvall, S. (2015). Physical literacy in the field of physical education - A challenge and a possibility. Journal of Sport and Health Science, $4(2), 113-$ 118.

doi:https://doi.org/10.1016/j.jshs.2015.0 2.001

McLennan, N., \& Thompson, J. (2015). Quality Physical Education (QPE): guidelines for policy makers Retrieved from

http://unesdoc.unesco.org/images/00 23/002311/231101E.pdf

Morgan, P., \& Bourke, S. (2008). Nonspecialist teachers' confidence to teach PE: the nature and influence of personal school experiences in PE. Physical Education and Sport Pedagogy, 13(1), 1-29. doi:10.1080/17408980701345550
Okely A. D., J, S., SA, V., D, C., A, T., M, T., . . . N, M. (2012). A systematic review to inform the australian sedentary behaviour guidelines for children and young people.

Pill, S. (2010). Sport literacy - It's not just about learning to play sport via 'textbook techniques'. Journal of Student Wellbeing, 4 (2), 32-42.

Pill, S., Penney D., \& Swabey K. (2012). Rethinking sport teaching in physical education: a case study of research based innovation in teacher education. Australian Journal of Teacher Education, 32(8), 118-138. doi:10.14221/ajte.2012v37n8.2

Puhse, E., \& Gerber, M. (2005). International comparison of physical education: Concepts, problems, prospects. Oxford: Meyer.

Siedentop, D., Hatsie, P., \& Mars, V. D. (2011). Complete guide to sport education (2nd Ed). IL.

United Nations Educational Scientific and Cultural Organisation. (2015). Quaity Physical Education (QPE): Guildelines for policy-makers. Retrieved from http://www.unesco.org/new/en/socia l-and-human-

sciences/themes/physical-educationand-sport/policy-project/

Wallhead, T., \& O'Sullivan, M. (2005). Sport Education: physical education for the new millennium? Physical Education and Sport Pedagogy, 10(2), 181-210. doi:10.1080/17408980500105098

Whitehead, M. (2013a). Definition of physical literacy and clarification of related. Journal of Sport Science and Physical Education - ICSSPE Bulletin, 65, 28-33.

Whitehead, M. (2013b). The history and development of physical literacy. Paper presented at the International Council of Sport Science and Physical Education (ICSSPE). 